\title{
A mídia e o golpe de 1964: revista O Cruzeiro como aliada do discurso das forças militares
}

\author{
Ercília Ana Cazarin ${ }^{1}$ \\ Eduardo Silveira de Menezes ${ }^{2}$
}

\begin{abstract}
By a documental file, this text works with the way like the $\mathrm{OCru}$ zeiro Magazine narrated the military blow occurred on March, $31^{\text {st }}, 1964$, in Brazil. The analysis is done by the special edition of the periodic, published on April, $10^{\text {th }}, 1964$, which gave exclusivity to the subject. So, we present a study of the main theories of journalism and the production conditions in what occurred these facts, resorting some Discourse Analysis concepts of French line. Finally, we mark the benevolence that the dominants classes are treaties by the biggest means of communication, as well as, the impact that the discursive formation (DF) what carries knowledge of this relation can exercise on the conjunct of the society.
\end{abstract}

Keywords: military blow; discourse analysis; journalistic discourse; documental file.

Resumo: Este texto, a partir de um arquivo documental, ocupa-se com a forma como a revista $O$ Cruzeiro narrou o golpe militar, ocorrido em 31 de março de 1964, no Brasil. A análise se dá por meio da edição especial do periódico, publicada no dia 10 de abril do mesmo ano, a qual concedeu exclusividade ao assunto. Para tanto, apresentamos um estudo das principais teorias do jornalismo e das condições de produção em que ocorreram os fatos, recorrendo a alguns conceitos da Análise de Discurso de linha francesa. Por fim, assinalamos a benevolência com que as classes dominantes são tratadas pelos grandes meios de comunicação, bem como o impacto que a formação discursiva (FD) que abriga saberes desta relação pode exercer sobre o conjunto da sociedade.

Palavras-chave: golpe militar; análise de discurso; discurso jornalístico; arquivo documental.

\section{Considerações iniciais}

Ao completar 50 anos do golpe de Estado que instaurou a ditadura militar no Brasil, evidenciamos a importância de revisitar o arquivo documental de matérias que foram veiculadas pela grande mídia durante aquele período. A instauração da Comissão Nacional da

1 Doutora em Letras pela Universidade Federal do Rio Grande do Sul (UFRGS). Professora do PPG-Letras da Universidade Católica de Pelotas - UCPEL. Membro do Laboratório de Estudos em Análise de Discurso - LEAD/UCPel e do Grupo de Estudos em Análise de Discurso - GEPAD-RS/UFRGS.

2 Doutorando no programa de PPG-Linguística Aplicada da Universidade Católica de Pelotas (UCPel) e membro do Laboratório de Estudos em Análise de Discurso (LEAD) na mesma instituição. Mestre em Ciências da Comunicação pela Universidade do Vale do Rio dos Sinos (Unisinos). Graduado em Jornalismo pela UCPel. 
Verdade - Lei n. ${ }^{\circ} 12.528$ de junho de 2012 - e as recentes manifestações de movimentos sociais em defesa do direito à verdade e justiça têm movimentado o cenário político nacional e encontram lugar na análise proposta por este estudo. O discurso que desperta o nosso interesse é o político, concebido como embate, relação de forças que se materializam pelo próprio discurso. E, arquivo é entendido aqui, a partir de Horta Nunes, "não como um conjunto de 'dados' objetivos dos quais estaria excluída a espessura histórica, mas como uma materialidade discursiva que traz as marcas da constituição dos sentidos” (2005, p.2).

Partindo desse material de arquivo é que realizamos a interpretação, tendo presente que a mesma não corresponde a uma interpretação unívoca - sempre pode ser outra. Refletindo sobre o Golpe de Estado em questão e atentando para a influência que os grandes meios de comunicação exerceram - e ainda exercem - sobre o conjunto da sociedade, o presente artigo analisa como uma das principais publicações da época retratou a tomada de poder pela via militar no Brasil. Trata-se da revista O Cruzeiro, um dos fenômenos editoriais que circulou em todo o território nacional por mais de 40 anos, sendo lida por variadas classes sociais. Para tanto, estamos utilizando a edição do dia 10 de abril de 1964, a qual se apresenta como a "Edição Histórica da Revolução".

De início, tratamos de alguns conceitos do jornalismo, passando por teorias importantes e evidenciando a definição discursiva de ideologia. De posse desses elementos, contextualizamos o objeto da análise e, posteriormente, investigamos as condições de produção que levaram à instauração de uma ditadura militar no Brasil. Logo a seguir, caracterizamos o discurso da revista O Cruzeiro, amparando-nos, principalmente, na Análise de Discurso (AD) com filiação em Pêcheux, teoria que julgamos indispensável para alcançar o objetivo proposto.

Este é, portanto, um convite para que o leitor realize uma incursão crítica na história política recente do nosso país. Incursão, esta, mediada pela materialidade da língua cuja inscrição de seus efeitos materiais na historicidade possibilita evidenciar os interesses políticos e culturais imersos na leitura de arquivo. Salientamos que, embora o objeto de análise - a revista $O$ Cruzeiro - não esteja mais em circulação, muitas das suas práticas de persuasão e vinculação ideológica continuam operando nos principais grupos de comunicação brasileiros; hoje, é bem verdade, sob a égide da ditadura do capital.

\section{0 jornalismo, a notícia e o componente ideológico}

No início do século XIX, com a expansão e o desenvolvimento da imprensa, ocorre um aumento significativo na comercialização de jornais, abrindo novas perspectivas para o principal meio de comunicação da época: a mídia impressa. Surge, assim, um novo paradigma, no qual os panfletos políticos, de orientação partidária - predominantes até o final do século XVIII - cedem espaço a outra forma de produção textual. Nesse contexto, a informação - agora vista como mercadoria - passa a ocupar lugar central na constituição do que se convencionou chamar de notícia (TRAQUINA, 2005).

A predominância deste espírito mercantil, aliada à intenção de reivindicar um caráter científico e legítimo no ato de concepção do material informativo, fez com que a notícia - produto oferecido pelos jornais - passasse a ser idealizada por uma fábrica seletiva de produção dos fatos. Neste ponto, é preciso atentar para o trabalho da ideologia, que, ao produzir evidência, condiciona a constituição dos sujeitos e dos sentidos. Ao compreender que "não há sentido sem interpretação", como nos diz Orlandi (2007, p.45), é possível inferir que todo discurso jornalístico, por se tratar de uma interpretação possível sobre determinado fato, não está livre de determinações culturais, políticas e econômicas. 
A chamada "linha editorial" dos jornais é, em nossa avaliação, assegurada pela memória institucionalizada e constitutiva dos grandes conglomerados de comunicação, os quais, ao longo da história, sempre estiveram aliados aos interesses dominantes. ${ }^{3}$

De acordo com Orlandi (2007, p. 48):

A ideologia, por sua vez, nesse modo de conceber, não é vista como conjunto de representações, como visão de mundo ou como ocultação da realidade. Não há, aliás, realidade sem ideologia. Enquanto prática significante, a ideologia aparece como efeito da relação necessária do sujeito com a língua e com a história para que haja sentido.

A atividade jornalística, tal qual estamos descrevendo neste estudo, considera que o texto noticioso costuma edificar-se dentro de uma concepção funcionalista. ${ }^{4}$ Portanto, os pressupostos de neutralidade, imparcialidade e objetividade, assumem o papel de condutores do esquema noticioso, propiciando o cenário ideal para uma prática profissional descolada da reflexão crítica. Devemos levar em conta que a origem e as motivações dessa corrente de pensamento "encontram-se em demandas sociais, de modo especial dos segmentos militares, governamentais, empresariais e dos partidos políticos" (GOMES, 2004, p. 64).

No início do século XX, surge na Europa uma corrente filosófica de pensamento marxista, que procura confrontar a teoria funcionalista, fazendo uma análise profunda da cultura de massa e da indústria cultural..$^{5}$ A Escola de Frankfurt torna-se responsável por elaborar o que ficou conhecido como teoria crítica, um contraponto necessário à visão da Escola Funcionalista, que assumiu abertamente a defesa dos interesses dos grupos dominantes. Ao comparar essas duas correntes de pensamento, Gomes (2004, p. 91) explica que, "enquanto a escola norte-americana se preocupava em estudar o grupo, pesquisando o comportamento humano, a escola europeia, da qual faz parte a teoria crítica, se preocupa com o estudo da produção, com o estudo do conteúdo, com a ideologia".

Ao passo que os funcionalistas reivindicam o caráter social dos meios, os adeptos da teoria crítica denunciam a dominação exercida por eles. Os objetos de estudo também diferem de uma corrente de pensamento para a outra e, assim, apenas a teoria crítica estuda o conteúdo das mensagens, ou seja, a relação ideológica estabelecida entre os diversos meios. Visto isso, torna-se necessário esclarecer que uma análise sobre as construções discursivas no âmbito dos textos jornalísticos, a qual pretendemos empreender com este estudo, deve necessariamente considerar a contribuição da corrente europeia como base epistemológica; em nosso caso, é bom ratificar, trata-se da teoria do discurso de filiação pecheutiana.

3 Prova disso - e, talvez, o caso mais emblemático desse tipo de relação durante a década de 1960 - pode ser verificada na parceria estabelecida entre as Organizações Globo - de propriedade da família Marinho - e a companhia de mídia norte-americana Time-Life. Segundo a legislação brasileira da época, era proibida "toda e qualquer participação ou orientação intelectual de grupos estrangeiros na administração de empresas brasileiras de comunicação". No entanto, a Rede Globo firmou dois contratos com essa empresa, dos quais recebeu um montante de cinco milhões de dólares. Os recursos foram destinados a equipar seus estúdios e desenvolver melhorias técnicas estruturais. Esse processo aprofundou a relação de dependência financeira e também cultural com as empresas multinacionais, já que eram importadas produções norte-americanas para serem veiculados no Brasil.

4 Conforme Wolf (1995, p. 56), “a teoria funcionalista ocupa uma posição muito precisa que consiste na definição da problemática dos mass media a partir do ponto de vista da sociedade e do seu equilíbrio, da perspectiva do funcionamento do sistema social no seu conjunto e do contributo que suas componentes (mass media incluídos) dão a esse funcionamento".

5 A indústria cultural é fruto da sociedade industrializada de tipo capitalista liberal. Mais especificamente, porém, a indústria cultural concretiza-se apenas numa segunda fase dessa sociedade, a que pode ser descrita como a do capitalismo de organização, (ou monopolista), ou ainda, como sendo a sociedade dita de consumo (COELHO, 1986, p. 29). 
Mesmo que de forma muito breve e sintética é importante dizer que a rotina produtiva do jornalista, em sua prática diária dentro das redações, é caracterizada por algumas teorias. Dentre elas, cumpre nosso dever ressaltar alguns aspectos do funcionamento de pelo menos quatro; são elas: a teoria do espelho, a teoria do gatekeeper, a teoria organizacional e a teoria do agendamento. Evidenciamos, no entanto, que "estas teorias não se excluem mutuamente, ou seja, não são puras ou necessariamente independentes umas das outras” (TRAQUINA, 2005, p.146).

A teoria do espelho, por exemplo, afirma que o jornalismo é uma espécie de autorretrato da realidade, não se deixando levar por outro fator que não a verdade. Nesta perspectiva, a informação desinteressada e honesta é o pressuposto básico da isenção, a qual é considerada viável e indiscutível por este método de análise. Já a teoria do gatekeeper mostra que o produto final da notícia é resultado de uma série de escolhas e decisões sobre a importância do fato a ser noticiado e a pertinência e/ou resultado dessa construção simbólica da realidade para o processo de formação da opinião pública (PENA, 2008). Segundo Traquina (2005), a partir desse estudo pode-se observar que a decisão de deixar passar ou filtrar determinada informação está intimamente ligada à "linha editorial" do veículo, ou seja, à carga ideológica que incide sobre ele.

Conforme nos lembra Orlandi (2007, p. 48):

O efeito ideológico elementar é a constituição do sujeito. Pela interpelação ideológica do indivíduo em sujeito inaugura-se a discursividade. Por seu lado, a interpelação do indivíduo em sujeito pela ideologia traz necessariamente o apagamento da inscrição da língua na história para que ela signifique produzindo o efeito de evidência do sentido (o sentido-lá) e a impressão do sujeito ser a origem do que diz.

Sendo assim, o efeito de que determinada interpretação do fato transformada em notícia decorre de um processo inerente ao ineditismo da construção textual, promovida pelo redator, é apenas ilusório. Em última análise, a informação é fruto das determinações ideológicas da própria "linha editorial” da empresa, a qual decorre da inscrição do veículo de comunicação em uma determinada formação discursiva, por sua vez determinada pelo interdiscurso, pela memória discursiva.

Além disso, a aceitação do enfoque e da proposta política da empresa, por parte dos repórteres e editores, estabelece uma relação de confiança entre todas as partes envolvidas no processo de construção da notícia. Por meio de um forte vínculo estabelecido entre o jornalista e a organização para qual trabalha, ocorre o processo de socialização organizacional. De acordo com Pena (2008), esse contato é objeto de estudo da teoria organizacional, que enfoca também a construção ideológica que habita o inconsciente do jornalista e permeia as relações de recompensa ou punição motivadas pela prática profissional.

Uma última análise sobre as teorias do jornalismo revela que os veículos de comunicação de massa são capazes de pautar a opinião pública ao mesmo tempo em que são assujeitados pela ideologia. Sabemos que os assuntos que circulam nas ruas, nos meios acadêmicos, profissionais e familiares obedecem a critérios previamente definidos pela grande mídia, sobretudo, com o intuito de garantir audiência. Essa teoria ficou conhecida como "agendamento", ou "agenda setting". Nascida nos Estados unidos, na década de 1970, tais pressupostos teóricos nos ajudam a refletir sobre a concepção equivocada de que os sujeitos seriam autônomos em relação a suas opiniões quanto ao governo, ao Estado e às políticas que julgam mais eficazes. Sabendo que o sujeito produz o seu discurso a partir de condições de produção dadas - nas quais também conta o interdiscurso - é possível dizer que os recortes com os quais os meios de comunicação operam estão condicionados pelo atravessamento ideológico, sendo determinados pelas relações de força que atuam no conjunto da sociedade. 


\section{As condições de produção do Golpe Militar}

Antes de caracterizar os momentos marcantes do golpe militar de 1964 e relacioná-los com a interpretação que a revista $O$ Cruzeiro deu a esse acontecimento histórico, em sua edição especial destinada ao tema, ressaltamos que a consolidação de um Estado autoritário, no Brasil, se dá pela relação entre os sujeitos envolvidos nesse episódio, o contexto sócio-histórico em que o fato ocorreu e a maneira com a qual a sociedade civil assimilou, por intermédio dos principais meios de comunicação, os dispositivos que desencadearam uma euforia anticomunista no país.

Essa observação se faz fundamental, pois, ainda hoje, experiências de totalitarismos são presentificadas para atender diferentes interesses político-partidários. Ao tratar dessa questão, Orlandi (2007, p.31) nos lembra que "todos esses sentidos já ditos por alguém, em algum lugar, em outros momentos, mesmo muito distantes, têm um efeito", o qual, segundo ela, está diretamente relacionado com "o que se diz" e o "a dizer". O funcionamento do discurso é, portanto, objeto da sua interconexão com os sujeitos e a ideologia. No eixo da formulação do discurso - o intradiscurso - a sociedade formula enunciados que respondam às suas angústias e preocupações relativas a um dado contexto sócio-histórico.

Nos momentos que precederam o golpe militar no Brasil, é claramente possível identificar esta relação. ${ }^{6}$ Atuando por meio da ajuda financeira norte-americana, os militares estabeleceram uma estratégia infalível. Entidades como o Instituto de Estudo e Pesquisas Sociais (IPES) e o Instituto Brasileiro de Ação Democrática (IBAD) passaram a ser financiadas com capital estadunidense e, dessa forma, protagonizaram uma ampla campanha contra o governo de João Goulart em todo o território nacional. Formou-se, assim, um complexo político-militar que ficou conhecido como IPES/IBAD. ${ }^{7}$

A ação do complexo IPES/IBAD dentro das Forças Armadas visava a neutralização do dispositivo popular de João Goulart e a minimização do apoio militar a diretrizes políticas socialistas e populistas. A elite orgânica foi também responsável por estimular, entre os militares, grupos favoráveis ao golpe. Sua ação foi sincronizada dentro de um plano geral, cujo alcance nem sempre era de total conhecimento de seus vários membros e participantes (DREIFUSS, 2008, p.382).

Para se ter uma ideia, a Folha de São Paulo, O Estado de São Paulo, a Globo, a Record, o Jornal do Brasil e o Correio do Povo são só alguns exemplos de organizações midiáticas que operavam dentro de uma corrente ideológica, articulada com a imprensa norte-americana, a fim de moldar a opinião pública na defesa dos interesses da elite nacional e do capital estrangeiro. Palestras, filmes e peças teatrais foram algumas das técnicas de divulgação e propaganda utilizadas pelo complexo IPES/IBAD para estimular a sociedade a compartilhar da sua posição ideológica.

É nesse ínterim, portanto, que a ditadura foi ganhando corpo até atingir o seu objetivo de tomar o poder. A classe média e os setores conservadores ligados a empresários e fazendeiros

6 Conforme Arns (1985), as ações militares e as estratégias de suas lideranças constituíram-se dentro do contexto político marcado pela Guerra Fria. O governo dos EUA entendia o papel estratégico que o Brasil ocupava na América Latina. Ter o domínio de todos os países da desta região consistia em adotar uma política mundial capaz de sobrepor os interesses do dispositivo sindical-militar, o qual ganhou destaque durante o governo de Jango.

7 "A história do complexo IPES/IBAD relata o modo pelo qual a elite orgânica da burguesia multinacional e associada evoluiu de um limitado grupo de pressão, para uma organização de classe, capaz de uma ação política sofisticada, bem como o modo pelo qual ela envolveu da fase de projetar uma reforma para o estágio de articular um golpe de Estado" (DREIFUSS, 2008, p.174). 
haviam se juntado aos militares e faziam coro à propaganda anticomunista. Hoje existe um consenso entre os principais historiadores da época de que o golpe, no Brasil, foi um golpe civil-militar. O respaldo de boa parte dos brasileiros ao golpe partiu da perspicácia com a qual a grande imprensa conseguiu povoar o imaginário da sociedade civil - em especial, da classe média - com o medo de regimes autoritários. As formas arbitrárias de governo foram sistematicamente associadas aos pressupostos socialistas que, segundo alardeavam, poderiam entrar em curso no país caso não fosse tomada uma medida.

Embora pertencente ao espectro ideológico oposto ao socialismo científico, proposto por Karl Marx e Frederich Engels, o Partido Nacional Socialista dos Trabalhadores Alemães (Partido Nazista) trazia em sua insígnia uma referência às palavras "socialista" e "trabalhadores", que foram demonizadas pelos militares brasileiros e associadas a esse e outros regimes totalitários. Alguns eram mais facilmente manipuláveis, como o Stalinismo, que acometeu à União das Repúblicas Socialistas Soviéticas (URSS) após a Revolução Russa. ${ }^{8}$ Aproveitando as condições de produção desse discurso de medo, as oligarquias da época levaram às ruas a campanha Marcha da Família, com Deus, pela Liberdade. ${ }^{9}$

As condições de produção do discurso patrocinado pelo governo de estado norte-americano e amplificado pela mídia corporativista estavam alicerçadas em uma série de acontecimentos que remetem ao início da década de 1960. Neste ano, João Goulart foi eleito vice-presidente pela segunda vez, graças a um acordo político capitaneado pelo PTB numa aliança com o PSD, a qual fazia oposição a UDN. O PTB, partido de Jango, tinha se tornado conhecido por adotar uma linha política populista e, ao mesmo tempo, reformista, durante a Era Vargas, o que conferia a João Goulart um papel de herdeiro natural deste programa político, criando, assim, expectativas a seu respeito.

Em 1961, quando Jânio Quadros renuncia à Presidência da República, os militares percebem uma boa chance de assumir as rédeas da nação. Nessa época, passa a ser defendido o impedimento da posse de Jango, para que fossem realizadas novas eleições. Para garantir a posse de Jango, no Rio Grande do Sul, um movimento de resistência política liderado pelo então governador do estado, Leonel Brizola, cria o que vai ficar conhecido como a Campanha da Legalidade..$^{10}$ No entanto, apenas em 1963, quando o bloco de poder formado pela UDN e o PSD já parecia ter tomado conta do cenário político, é que Jango procura construir um governo nacional-reformista, amparando-se nas camadas populares e na classe trabalhadora (DREIFUSS, 2008).

O governo de Goulart durou pouco mais de dois anos. Sem nenhum tipo de organização ou comando, estudantes e trabalhadores, que eram contra o golpe de Estado, percebendo sua iminência, foram às ruas para tentar resistir, mas ficaram atirados à própria sorte. Em $1^{\circ}$ de abril de 1964 , os militares conseguiram, enfim, chegar ao poder. Com isso, abriu-

8 Conforme lembra Tragtenberg (1998, p.134), “Após a morte de Lenin e a ascensão de Stalin ao poder, este expulsará Trotski da URSS, perseguirá seus adeptos organizados como Oposição de Esquerda, pressionará outros à retratação e porá em prática a tese da industrialização acelerada do trotskista Preobranjeski. O pequeno proprietário de terras, criado pela Reforma Agrária de Lenin, será enquadrado em fazendas estatais".

9 Organizado nos primeiros meses de 1964, o movimento procurou sensibilizar a opinião pública contra as medidas adotadas pelo governo João Goulart. O temor "anticomunista" foi alardeado a partir do anúncio das reformas de base e encontrou respaldo na classe média da época. Assim, o pedido de deposição do presidente legalmente constituído atendia aos interesses dos Estados Unidos e facilitava a aceitação da instauração de um governo militar.

10 Com a renúncia de Jânio Quadros à presidência da República, uma crise política se abateu sobre o Brasil. No Rio Grande do Sul, o então governador do estado, Leonel Brizola, cunhado de João Goulart, realizou uma grande mobilização popular a fim de garantir a manutenção da ordem institucional que previa a posse do vice-presidente. No entanto, Jango estava na China e não pôde assumir o cargo tão logo Quadros se afastou do poder. Para bem da verdade, é importante dizer que a posse de Jango foi assegurada por um grupo de políticos, industriais e ruralistas do sul do Brasil, o que não foi suficiente para romper com a ideologia dominante. As cartas continuaram a ser dadas pelos militares, buscando implementar seu plano de governo. 
-se a possibilidade para a concentração de renda através de um novo modelo econômico baseado na desnacionalização da economia.

No dia 9 de abril, decretou-se o primeiro Ato Institucional do governo militar. Este dispositivo definiu que o novo presidente seria eleito de forma indireta e poderia concluir o mandato iniciado por Jânio Quadros. Depois, as eleições deveriam voltar a ser realizadas pelo voto direto, mas isso não foi o que aconteceu. Ao nomear o general Castelo Branco, o Congresso Nacional dá início a um longo ciclo de presidentes militares que acabam revezando-se no poder. A ditadura militar só teve fim mais de 20 anos depois, quando foi retomada a democracia.

\section{0 discurso da revista O Cruzeiro sobre o golpe}

De posse do que já foi exposto até este momento, entendemos que a questão ideológica está intrinsecamente ligada a toda atividade jornalística. Partindo da compreensão de que a linguagem não é neutra e que textos, títulos, enunciados, legendas e imagens são fortemente determinados pela ideologia, é possível analisar o funcionamento do discurso utilizado pela revista $O$ Cruzeiro, ao tratar do golpe militar de 1964, em sua edição especial de 10 abril do referido ano.

Muito antes dessa data, em dezembro de 1928, o empresário Assis Chateaubriand tentava expandir seu império da comunicação no sul do país, com a compra do Diário de Notícia. A falta de êxito nesse projeto o levou a investir numa publicação que pudesse atingir todo o território nacional; nascia, a partir daí, O Cruzeiro, que com o passar dos anos se consagrou como uma nova forma de fazer jornalismo em revista no Brasil. O semanário foi um dos mais lidos em território nacional até entrar em decadência na década de 1970. Com uma boa diagramação, a revista apresentava uma estética diferente dos outros magazines da época. No final da década de 1930, graças ao esforço de Chateaubriand, O Cruzeiro já estava sendo comercializado em todas as grandes cidades brasileiras. ${ }^{11}$

Ao nos dedicarmos à análise do discurso de $O$ Cruzeiro, procuramos considerar, sobretudo, o seu editorial, pois este referencia todas as reportagens publicadas pelo periódico. Escrito por David Nasser, redator principal na época do golpe militar, sob o título "Saber Ganhar", o texto demonstra a posição política e ideológica do semanário. Vale lembrar que os enunciados reportados no transcorrer da publicação obedecem a uma ordem cronológica e remetem ao que foi elucidado por Nasser nesse momento de apresentação da edição especial.

Durante a análise nossa compreensão foi a de que, embora fosse possível seguir por caminhos diversos, todos estariam imbricados em dois pontos centrais, os quais optamos em dividir de acordo com o seguinte:

- Legitimação do golpe;

- Afirmação dos ideais anticomunistas.

Como o tipo de discurso analisado é o político, salientamos que, em conformidade com Corten (199, p.37), "por representação do político designaremos aqui a cena das forças políticas construídas pelo discurso". Isto é, para nós, um espaço onde os elementos que operam na sociedade são vistos como "forças políticas". Segundo o autor, o político se manifesta justamente na correlação de forças estabelecidas socialmente, sendo uma representação destinada a delimitar o fechamento de uma cena. Na análise, as particularidades dos enunciados analisados são entendidas como Sequências Discursivas de Referência (SDR).

11 CADERNOS da comunicação, O Cruzeiro - A maior e melhor revista da América Latina, Série Memória, vol. 3, Rio de Janeiro, 2002. 


\section{Conexão Letras}

\subsection{Legitimação do golpe}

Nas primeiras páginas de $O$ Cruzeiro, é possível compreender a benevolência com que são tratados os políticos e os militares que comandaram o golpe de 1964 no Brasil. A capa da revista traz a foto do então governador de Minas Gerais, Magalhães Pinto; sorridente, ele recebe um beijo de sua nora, Terezinha de Magalhães, o gesto simboliza a felicitação por uma conquista (Foto 1).



Foto 1

A partir daí, Magalhães Pinto é reverenciado pela publicação como um mártir, o que pode ser evidenciado com mais precisão na reportagem assinada por Oswaldo Amorim, Luis Alfredo e José Nicolau sob o título "Magalhães o Herói da Revolução", a qual ocupa as páginas 12 e 13 da revista (Foto 2). Nesta matéria, o governador mineiro é apresentado como o responsável por iniciar o movimento que levaria ao afastamento do presidente João Goulart. Tal feito é reportado como "a histórica arrancada pelas liberdades democráticas" e seu precursor é tido como "o grande herói da insurreição vitoriosa".

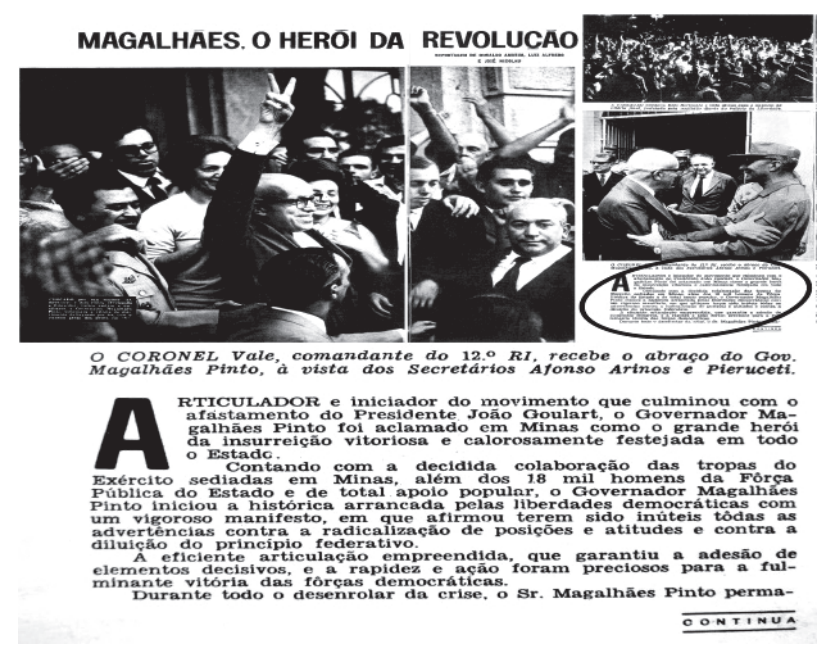

Foto 2

A partir da leitura do material apresentado, evidenciamos a clara intenção de $O$ Cruzeiro em legitimar a figura de Magalhães Pinto através de uma justificativa para os seus atos 
que é dita como heroica. Segundo a publicação, ele seria "digno do apoio das massas". Tal assertiva é confirmada pela literatura de Thompson (2000), quando afirma que as relações de dominação apresentam-se de forma legítima ao conjunto da sociedade e sustentam-se porque são descritas como merecedoras de apreço do povo.

Acontece que para essas situações se consolidarem, precisam estar de acordo com a ideologia dominante. Neste caso, no entanto, por mais que João Goulart estivesse ocupando a Presidência da República, as classes dominantes eram necessariamente contrárias a ele, ou seja, tais forças políticas encontravam-se na elite orgânica empresarial e nos oficiais que ocupavam os mais altos postos dentro da hierarquia militar - esse era o jogo de forças políticas em cena.

\subsection{Afirmação dos ideais anticomunistas}

Para compreender melhor a relação intimista que $O$ Cruzeiro mantinha com as lideranças políticas e militares favoráveis ao golpe, será preciso recorrer novamente ao editorial da revista, que está nas páginas 4 e 5 (Foto 3). O texto representa a posição ideológica da publicação, já que todas as outras reportagens interagem, de alguma forma, com o que foi exposto nos enunciados em destaque. O referido artigo cita um por um os principais articuladores do golpe e apresenta uma construção textual semelhante às que se encontram hoje nos editoriais das mais destacadas revistas nacionais.

Analisando o texto, é possível perceber que Nasser emprega constantemente a terceira pessoa do plural, "eles", em contraposição à primeira, "nós", de forma a separar os grupos que estavam tentando chegar ao poder de seus oponentes. Isso é o que Thompson (2000) chama de fragmentação e que, nós analistas de discurso, entendemos como jogo de forças materializado no discurso. Posicionando-se ao lado dos golpistas, o redator evoca-os por suas particularidades, realçando as ações de ataque ao Governo Jango. Quando o repórter de O Cruzeiro se refere ao antigo governador de Minas Gerais, por exemplo, o faz através do seguinte enunciado: "agora eles sabem que sua coragem não se conta pelos fios de cabelo, ó indecifrável Magalhães Pinto" (SDR 1, Foto 3). Em outra passagem, o governador da Guanabara, ferrenho opositor de Jango, é lembrado desta forma: "agora eles sabem que suas palavras não eram simples filigranas verbais, Governador Carlos Lacerda” (SDR 2, Foto 3).

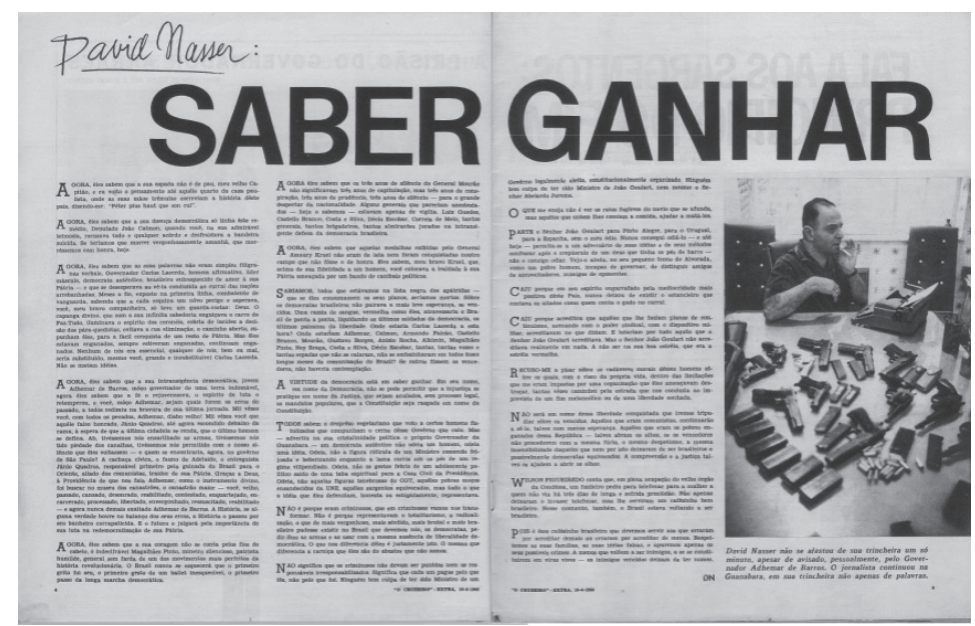

Foto 3 
Para interpretar a formação discursiva (FD) de $O$ Cruzeiro, no que tange a sua posição ideológica, deve-se recorrer insistentemente ao editorial de David Nasser (Foto 3), o qual afirma que é preciso dar atenção "as figuras tenebrosas". A citação é uma referência do jornalista à União Nacional dos Estudantes (UNE) e à Central Geral dos Trabalhadores (CGT). As expressões de agressividade nos permitem produzir o sentido de medo existente, entre os tradicionais setores do empresariado brasileiro, de que uma nova forma de governo tomasse conta do Brasil. No oitavo parágrafo do editorial da revista, um enunciado em particular chama a atenção; ao apelar para o sensacionalismo e dar ares dramáticos à vitória das classes dominantes, o redator afirma: "Sabíamos todos que estávamos na lista negra dos apátrias - que se eles consumassem seus planos seríamos mortos" (SDR 3, Foto 3).

Reforçando sua postura anticomunista, O Cruzeiro utiliza expressões como: "jugo vermelho" ou "erva daninha da infiltração comunista", as quais criavam no ideário nacional um sentimento de repulsa pelas propostas socialistas. Em um dos discursos mais inflamados que são reproduzidos pela publicação, retomando a linha editorial da revista, o governador de São Paulo Adhemar de Barros, afirma: "caçaremos os comunistas por todos os lados do país". Referindo-se ao que chama de "pelegos, estudantes vermelhos, os camponeses doutrinados e os escravos de Moscou", o governador de São Paulo explica que sua intenção é mandá-los para uma viagem à Rússia, segundo ele, "uma viagem que não terá volta".

A metáfora da "viagem que não terá volta" nos leva a Pêcheux (1988, p. 263), quando, ao conceber o discurso como efeito de sentidos entre interlocutores, e, ao nos alertar para o fato de que "o sentido não se engendra a si próprio, mas se produz no non-sens", nos abre a possibilidade para a compreensão de que o sentido sempre pode vir a ser outro, pode romper com os sentidos já naturalizados. "Os sentidos só existem nas relações de metáfora (...) as palavras, expressões, proposições recebem seus sentidos das formações discursivas nas quais se inscrevem" (ORLANDI, 1996, p. 21). Sendo assim, em uma FD oposta ao discurso do golpe militar, pelo viés da memória discursiva, emergem, do interdiscurso, efeitos de sentidos outros, ou seja, aqueles dos horrores praticados pela ditadura - brasileiros mortos e desaparecidos que efetivamente nunca mais voltaram.

No editorial escrito por Nasser - e repetidamente nos textos que seguem -, podemos compreender que ao optar pelo pronome "nós", a revista se refere não apenas aos políticos e militares que articularam o golpe, mas simula a inclusão da sociedade civil. Conforme já abordado em outra oportunidade, ${ }^{12}$ quando se trata do discurso, a utilização do pronome "nós", equivale a "eu” mais "outra(s) pessoa(s)", sendo, em uma única sílaba, auto e hetero designativo; "nós" é a primeira encarnação do "mais de um" (GEFFROY, 1985, p. 5). De acordo com Cazarin (2004, p. 188), "“nós” tem, com frequência, o papel de um "locutor coletivo", embora suas funções nem sempre se limitem àquelas do dizer”. Evidenciamos, ainda, que, por se tratar de uma forma pronominal rica em potencialidades dialógicas, a análise de seu funcionamento discursivo coloca duas questões centrais: "quais pessoas $o$ "nós" convoca para si e porquê?".

Além disso, é necessário se ater a outro pronome, o qual foi citado de forma exaustiva no editorial "Saber Ganhar". Quando Nasser fazia referência a "eles", a quem exatamente estava se dirigindo? Sabe-se que quando o fazia era sempre com o intuito de criticá-los, ofendê-los e, por horas, dissimular sobre suas ideias. Como comprovam os enunciados a seguir: "Não é porque representavam o totalitarismo, a radicalização, o que de mais vergonhoso, mais sórdido, mais brutal e mais brasileiro pudesse existir no Brasil que devemos

12 CAZARIN, Ercília Ana. Identificação e representação política: uma análise do discurso de Lula (19781998). Tese de doutoramento. Instituto de Letras. UFRGS, 2004. 
nós, os democratas, pedir-lhes as armas e as usar com a mesma ausência de liberdade democrática", (SDR 4, Foto 3) "Respeitemos as suas famílias, as suas ideias falsas, e apuremos apenas os seus crimes" (SDR 5, Foto 3).

O que chama atenção neste caso é que, em nenhum momento, o sujeito enunciador explica o que seria a "radicalização" ou quais seriam os "crimes" que supostamente teriam sido praticados. As agressões e as críticas não são contextualizadas, evidenciando-se, ainda que não de forma explícita, um preconceito na forma como o redator se coloca diante de seus adversários. Aliás, a falta de esclarecimento das práticas subversivas e a utilização de expressões com caráter pejorativo são uma constante nos textos desta edição de $O$ Cruzeiro.

\section{Apontamentos finais}

Durante a análise do discurso da revista $O$ Cruzeiro, foi possível identificar sentidos que se reproduzem, se repetem, se (re)significam ainda hoje, através dos grandes meios de comunicação. As forças políticas que agiram ativamente na deposição do presidente João Goulart atuavam em benefício do capital estrangeiro, criando um distanciamento moral com aqueles que se atreviam a questionar esse modelo de sociedade. O discurso de O Cruzeiro que, além de conservador, na maior parte dos casos, se mostrou preconceituoso e agressivo, resulta de uma memória discursiva na qual o mundo estaria dividido em dois extremos - de um lado o capitalismo (sistema político considerado ideal) e, de outro, o comunismo (considerado antidemocrático e, portanto, prejudicial). É o que a doutrina persa chama de maniqueísmo, ou seja, de um lado estaria todo o bem e, de outro, todo o mal. Assim, $O$ Cruzeiro, símbolo da constelação celestial, a qual está estampada na bandeira do Brasil, entendia equivocadamente que estava alinhado com as "forças do bem" e combatia as "forças do mal".

Em fevereiro de 2009, ao empregar o termo "ditabranda", em editorial, o jornal Folha de São Paulo recorreu à memória discursiva de $O$ Cruzeiro. A intenção era combater um discurso que estava sendo retomado no processo histórico da luta socialista travada na Venezuela. O caráter eufêmico do discurso de um dos principais jornais do Brasil, ao tratar da formação ideológica responsável pelo golpe militar no Brasil, procurava estabelecer uma relação de confrontação à vitória de Chávez nas eleições daquele ano; diga-se de passagem, uma escolha referendada nas urnas - pela via democrática. Sob determinadas condições de produção e recorrendo ao esquecimento ideológico, o mesmo discurso utilizado pela revista O Cruzeiro continua arregimentando adeptos, pois, ainda hoje, se faz presente no imaginário social. De nossa parte, consideramos importante ressaltar que nós, analistas, também não estamos fora da interpretação e, por conseguinte, da história. Importa, então, compreender que nossa interpretação se dá de acordo com os saberes próprios ao "lugar social" em que estamos inscritos - intervém aí a ideologia e o inconsciente como constitutivos do dizer, do interpretar. E, desse processo advém a possibilidade de outra(s) interpretação(ões).

\section{Referências}

CADERNOS da comunicação, O Cruzeiro - A maior e melhor revista da América Latina, Série Memória, vol. 3, Rio de Janeiro, 2002.

CAZARIN, Ercília Ana. Identificação e representação política: uma análise do discurso de Lula (1978-1998). Tese de doutoramento. Instituto de Letras. UFRGS, 2004. 


\section{Conexão Letras}

COELHO, T. O que é Indústria Cultural. 8 ed. São Paulo: Brasiliense, 1986.

CORTEN, André. Discurso e representação do político. In: Os múltiplos territórios da análise do discurso. Freda Indursky e Maria C. Leandro Ferreira (Orgs.). Tradução de Ana Maria Lisboa de Mello e Maria Regina Borges-Osório. Porto Alegre, RS: Sagra Luzzatto, 1999.

DREIFUSS, René Arnand. 1964 a conquista do Estado: ação política, poder e golpe de classe. 7. ed., Petrópolis: Vozes, 2008.

GEFFROY, Annie. Les nous indistincts. In: Mots (10), Paris, mars, 1985.

GOMES, Pedro Gilberto. Tópicos da teoria da comunicação: processos midiáticos em debate. 2. ed. São Leopoldo: Editora da UNISINOS, 2004.

HORTA-NUNES, José. Leitura de arquivo: historicidade e Compreensão. Disponível in : http://www.ufrgs.br/analisedodiscurso/anaisdosead/2SEAD/SIMPOSIOS/JoseHortaNunes.pdf Acesso em 16/11/2013.

ORLANDI, Eni Pulcinelli. Interpretação; autoria, leitura e efeitos do trabalho simbólico. Petrópolis, RJ: Vozes, 1996.

. Análise de discurso: princípios \& procedimentos. 7. ed. Campinas: Pontes, 2007. PÊCHEUX, Michel. Semântica e Discurso (1975). Tradução de Eni Pulcinelli Orlandi... [et.al.].Campinas, SP: Ed. da UNICAMP, 1988.

PENA, Felipe. Teoria do jornalismo. 2. ed., São Paulo: Contexto, 2008.

PEREGRINO, Nadja. O Cruzeiro: a revolução da fotorreportagem. Rio de Janeiro:

Ágil/Dazibao, 1991.

THOMPSON, John B. Ideologia e cultura moderna: teoria social crítica na era dos meios de comunicação de massa. 4. ed., Petrópolis: Vozes, 2000.

TRAGTENBERG, Maurício. A Revolução Russa. 2. ed. São Paulo: Editora UNESP, 2007.

TRAQUINA, Nelson. Teorias do jornalismo: porque as notícias são como são. 2. ed. Florianópolis: Insular, 2005.

WOLF, Mauro. Teorias de comunicação. 4. ed. Lisboa: Presença, 1995. 